\title{
APLICAÇÃO DA CONDUTÂNCIA LONGITUDINAL NA ESTIMATIVA DA VULNERABILIDADE NATURAL DO SISTEMA AQUÍFERO GUARANI NO ESTADO DE SÃO PAULO
}

\author{
APPLICATION OF LONGITUDINAL CONDUCTANCE IN THE ESTIMATION OF THE \\ NATURAL VULNERABILITY OF THE GUARANI AQUIFER SYSTEM IN THE SÃO PAULO \\ STATE
}

\section{Antonio Celso de Oliveira BRAGA ${ }^{1}$, Richard Fonseca FRANCISCO², Carlos Alberto BIRELLI ${ }^{3}$, Régis Gonçalves BLANCO ${ }^{3}$}

${ }^{1}$ Instituto de Geociências e Ciências Exatas, Universidade Estadual Paulista, UNESP, Rio Claro (SP), Brasil. Email: acobraga@rc.unesp.br

${ }^{2}$ Pós-Graduação em Geociências e Meio Ambiente, Instituto de Geociências e Ciências Exatas, Universidade Estadual Paulista, UNESP, Rio Claro (SP). Email: richardfon1 @ hotmail.com Instituto de Pesquisas Tecnológicas do Estado de São Paulo - IPT, São Paulo (SP) Email: birelli@ipt.br; rblanco@ipt.br

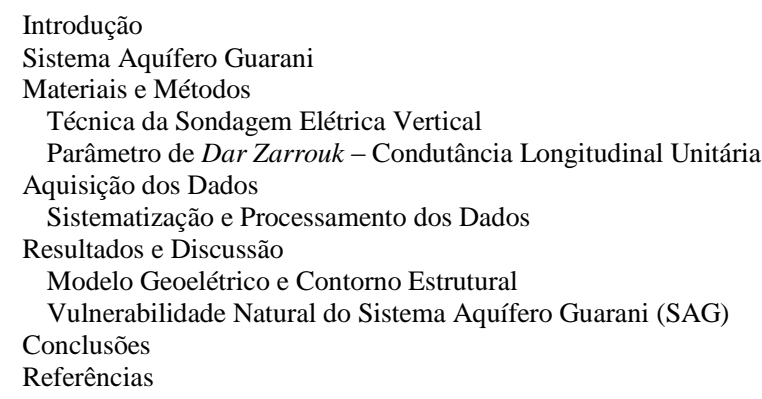

RESUMO - Este trabalho apresenta os resultados provenientes do processamento de dados geofísicos, adquiridos através de sondagens elétricas verticais desenvolvidas na área de ocorrência do Sistema Aquífero Guarani (SAG), no Estado de São Paulo, Brasil. Estes ensaios geoelétricos foram realizados pelo Instituto de Pesquisas Tecnológicas (IPT) nas décadas de 1970 e 1980. O objetivo deste trabalho foi avaliar a vulnerabilidade natural do Sistema Aquífero Guarani no Estado de São Paulo, através do parâmetro geofísico condutância longitudinal unitária. Os ensaios geofísicos aliados a dados de poços tubulares produziram resultados consistentes, em termos de caracterização da geologia regional e delineamento do contorno estrutural. Conforme o mapa de vulnerabilidade natural, as regiões mais vulneráveis estão situadas na área de afloramento do SAG, resultado compatível com aqueles reportados em trabalhos anteriores, a partir do emprego de outros modelos de avaliação. Regiões menos vulneráveis se concentram na porção central da bacia sedimentar (área de confinamento do SAG). Portanto, a utilização da condutância longitudinal unitária produziu resultados robustos, representando um parâmetro bastante promissor na estimativa da vulnerabilidade natural de aquíferos. Assim, é viável sua aplicação como alternativa aos modelos tradicionais, principalmente em regiões com escassez de dados, constituindo uma importante ferramenta para a proteção de aquíferos.

Palavras-chave: Geofísica, Condutância Longitudinal Unitária, Vulnerabilidade, Sistema Aquífero Guarani.

\begin{abstract}
This paper presents the results obtained from geophysical data processing, which were acquired through vertical electrical soundings developed on occurrence area of the Guarani Aquifer System (GAS), in São Paulo state, Brazil. The Institute Technological Research (IPT) carried out these geoelectric data in the 1970s and 1980s. This work aimed to assess the natural vulnerability of the Guarani Aquifer System in São Paulo state. The geophysical surveys coupled to wells data produced consistent results, in terms of characterization of the regional geology and delineation of structural outline. According to the natural vulnerability map, the most vulnerable regions are located in the unconfined GAS. This result is compatible with those reported in previous studies, based on the use of other assessment models. Less vulnerable regions are concentrated in the central portion of the sedimentary basin (confinement GAS). Therefore, the use of longitudinal unit conductance produced robust results, representing a very promising parameter for estimating the natural vulnerability of aquifers. Thus, its application is feasible as an alternative to the traditional models, especially in regions with scarcity data, constituting an important tool for the protection of aquifers.
\end{abstract}

Keywords: Geophysics, Longitudinal Unit Conductance, Vulnerability, Guarani Aquifer System.

\section{INTRODUÇÃO}

O incremento na demanda por águas subterrâneas, somado ao aumento do número de áreas contaminadas, induzem o desenvolvimento e aplicação de técnicas de investigação de aquíferos, a fim de contribuir para a sua proteção e uso racional da água, inclusive subsidiar o planejamento e implementação de projetos de remediação.
Neste contexto, insere-se o Sistema Aquífero Guarani (SAG) como uma importante fonte de abastecimento a diversos municípios do oeste paulista e indústrias de vários setores que demandam vazões significativas de consumo. É imprescindível destacar que a qualidade das águas deste aquífero vem sendo comprometida, em virtude de práticas inadequadas de uso e 
ocupação territorial em regiões naturalmente mais vulneráveis à contaminação, como as áreas de recarga direta do SAG (Gomes, 2008); (Albuquerque Filho et al., 2011).

Conceitualmente, o termo "vulnerabilidade natural" é definido como sendo a suscetibilidade de um aquífero ser afetado por uma carga contaminante aplicada na superfície do terreno, sendo determinada pelas características intrínsecas dos estratos acima da zona saturada (Foster \& Hirata, 1988); (Foster et al., 2006).

Sem dúvida alguma, a importância da realização de estudos de vulnerabilidade natural e perigo de contaminação das águas subterrâneas é inquestionável, pois a remediação de uma área tende sempre a ser difícil e impraticável em diversas situações, sob o âmbito financeiro, técnico e operacional.

Portanto, trabalhos desta natureza devem ser conduzidos, na medida em que permitem estimar áreas mais sensíveis à poluição, além de viabilizarem a identificação e a sistematização de fontes com maior potencial de contaminação. Desse modo, é possível planejar melhor a instalação e a operação de empreendimentos potencialmente nocivos aos aquíferos, destacando regiões prioritárias para o delineamento e implementação de um conjunto de medidas protetivas para as águas subterrâneas.

Ao longo das últimas décadas, foram desenvolvidos vários métodos para estimar a vulnerabilidade natural de aquíferos, cada um considerando fatores específicos para as áreas estudadas, sendo que nenhum pode ser considerado o mais adequado para todos os contextos hidrogeológicos.

De um modo geral, todos os modelos de avaliação foram projetados para fornecer um subsídio inicial aos órgãos ambientais de controle, quanto à definição de restrições para a implantação de atividades ou empreendimentos com elevado potencial de contaminação. Aos usuários, estão disponíveis desde os que utilizam muitos parâmetros de entrada, como os métodos DRASTIC (Aller et al., 1987) e SINTACS (Civita \& De Maio,
1997), àqueles mais simples, tais como: GOD (Foster \& Hirata, 1988); AVI (Van Stempvoort et al., 1992) e S (Braga \& Francisco, 2014).

Recentemente, alguns trabalhos demonstraram resultados bastante favoráveis à utilização do parâmetro de Dar Zarrouk denominado condutância longitudinal unitária $\left(\mathrm{S}_{\mathrm{i}}\right)$ na estimativa do "grau de proteção" ou "vulnerabilidade natural" de aquíferos, frente a contaminantes migrando verticalmente pela zona não saturada a partir da superfície do terreno, podendo ser mencionados: Braga \& Francisco (2014); Sendròs et al. (2014); Akpan et al. (2015); Ndatuwong \& Yadav (2015); Niaz et al. (2016); Mosuro et al. (2016) e Gemail et al. (2017).

O parâmetro geofísico condutância longitudinal unitária representa a razão entre as espessuras e resistividades elétricas das camadas sobrejacentes ao aquífero de interesse. Na prática, uma camada sobrejacente com valor de $S_{i}$ elevado (superior a 1,0) oferece alto grau de proteção à contaminação do aquífero, pois quanto maior a espessura desta camada, maior o tempo de infiltração do contaminante (maior filtro) e quanto menor sua resistividade, mais argiloso e menos permeável é o material (Braga et al., 2006).

A condutância longitudinal unitária fornece uma estimativa preliminar sobre a vulnerabilidade dos aquíferos, subsidiando detalhamentos posteriores em fases contínuas subsequentes. Por integrar o conjunto de produtos da execução de sondagens elétricas verticais, este parâmetro geofísico pode ser obtido para avaliações de áreas extensas, a custos e prazos reduzidos, o que representa umas de suas principais vantagens em relação a perfurações e amostragem de poços tubulares.

Mediante o exposto, o objetivo deste trabalho foi avaliar a vulnerabilidade natural do Sistema Aquífero Guarani (SAG) no Estado de São Paulo, por meio da condutância longitudinal unitária, considerando o pacote de rochas sobrepostas ao aquífero (sedimentos do Grupo Bauru e basaltos da Formação Serra Geral) e os sedimentos da área de afloramento do SAG.

\section{SISTEMA AQUÍFERO GUARANI}

O Sistema Aquífero Guarani (SAG) é considerado um dos maiores reservatórios de águas subterrâneas do mundo, estendendo-se pela Argentina, Paraguai, Uruguai e Brasil, que por sua vez, concentra $71 \%$ da superfície total do SAG
(Figura 1). Em território brasileiro, o SAG abrange parcialmente os Estados do Rio Grande do Sul, Santa Catarina, Paraná, São Paulo, Minas Gerais, Mato Grosso, Mato Grosso do Sul e Goiás (OEA, 2009). 


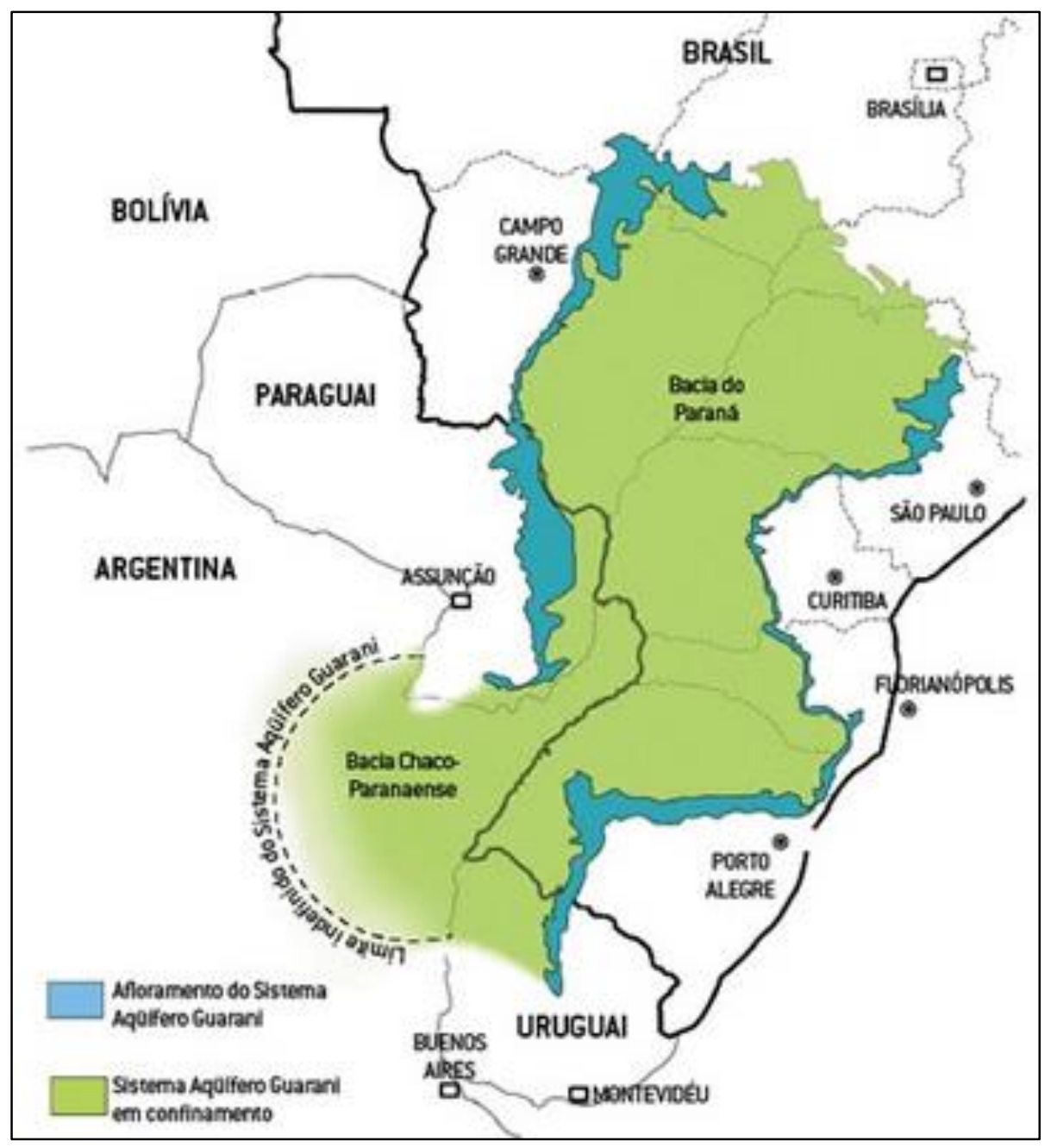

Figura 1 - Mapa de localização e limites do SAG. Fonte: CPRM (2014).

No Estado de São Paulo, a área de ocorrência do SAG (afloramento e confinamento) é estimada em aproximadamente $190.000 \mathrm{~km}^{2}$. A leste, está localizada a faixa aflorante $\left(16.000 \mathrm{~km}^{2}\right)$, que se estende desde o município de Rifaina, a norte, até Fartura, ao sul. Para oeste da área de afloramento, ocorre a área de confinamento do SAG, com uma extensão de cerca de $174.000 \mathrm{~km}^{2}$ (DAEE et al., 2005). O confinamento deve-se à superposição dos basaltos da Formação Serra Geral aos sedimentos componentes do aquífero, inclusive à existência de rochas sedimentares de baixa permeabilidade do Aquiclude Passa Dois, que se situam na porção basal do SAG (IPT, 2011). A Figura 2 apresenta as áreas de afloramento e confinamento do SAG, no âmbito do Estado de São Paulo.

O SAG tem uma espessura média de 250 metros, variando de poucos metros (nas bordas da bacia) a aproximadamente $800 \mathrm{~m}$ (em sua parte central), como nas porções norte dos Estados de São Paulo, Paraná e ao sul do Estado de Mato Grosso do Sul. A profundidade de seu topo, em relação ao nível do solo, varia de zero (região de afloramento) até $1.000 \mathrm{~m}$ na Argentina (Araújo et al.,1999); (Gastmans et al., 2012).

A litoestratigrafia que constitui o SAG data de cerca de 130 milhões de anos e, no contexto da Bacia Sedimentar do Paraná no Brasil, compreende as formações Pirambóia e Botucatu, que representam a base e o topo do aquífero, respectivamente (IPT, 2011). A Figura 3 apresenta uma seção estratigráfica típica do SAG, considerando o contexto da bacia do Paraná.

Em geral, a Formação Pirambóia reúne arenitos finos a muito finos, subfeldespáticos, com estratificação cruzada de porte variável, além de pacotes métricos sub-horizontais de arenitos muito finos, limoníticos, geralmente bioturbados ou preservando laminação paralela formada pela migração de ondulações eólicas. Estas litologias caracterizam um conjunto de fácies de dunas eólicas, interdunas (principalmente úmidas, subordinadamente secas e aquáticas) e lençóis de areia, comumente em interação com depósitos de canal e planícies de inundação fluvial (CaetanoChang, 1997). 


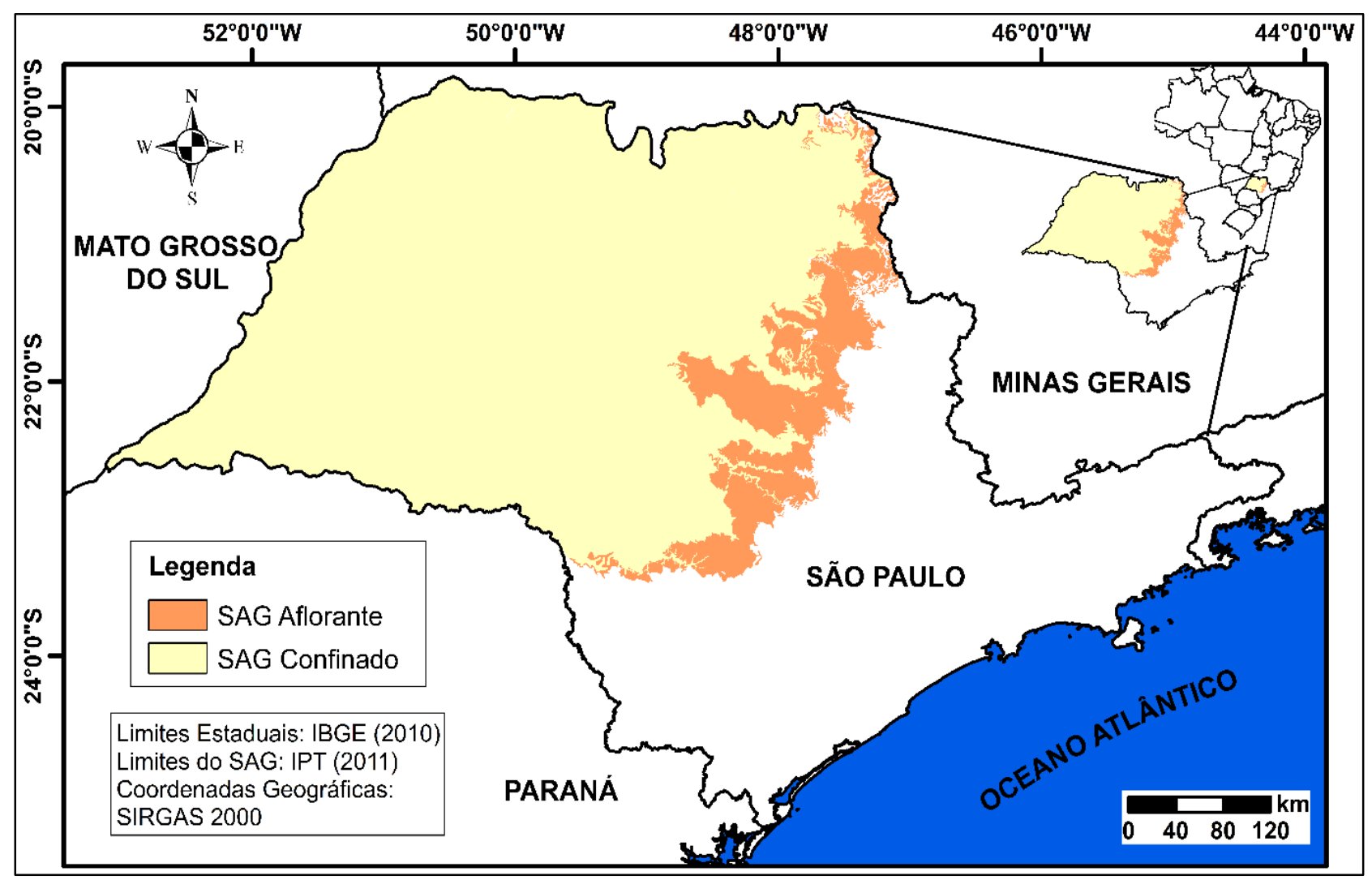

Figura 2 - Mapa de localização da área de estudo.

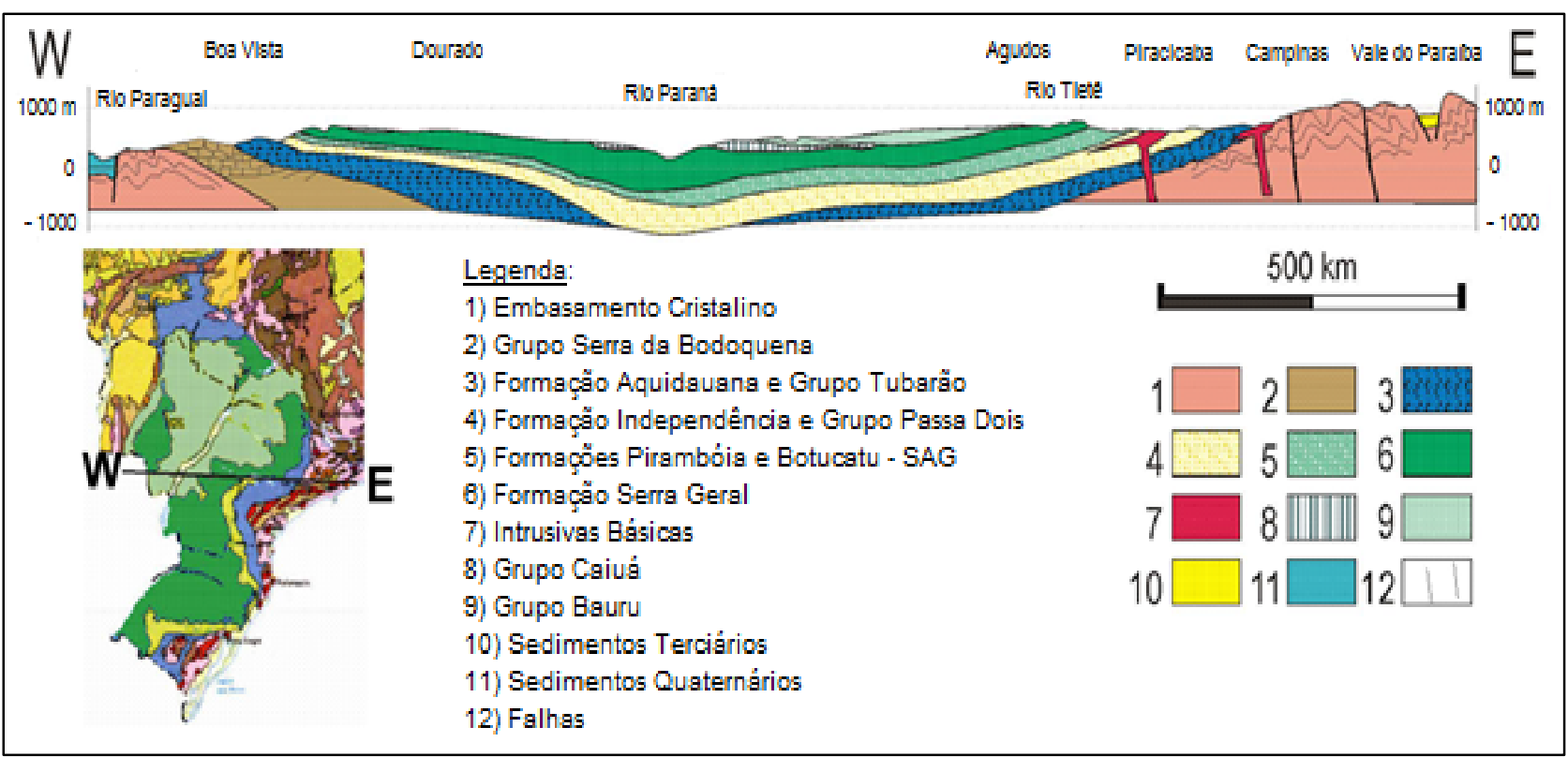

Figura 3 - Unidades estratigráficas componentes do Sistema Aquífero Guarani e da Bacia Sedimentar do Paraná em perfil EW. Fonte: Adaptado de Carneiro \& Oliveira (2008).

A Formação Botucatu é constituída por arenitos com granulação fina a média, avermelhados, bem selecionados, com estratificação cruzada, planar ou acanalada, de médio a grande porte (campos de dunas eólicas), com raras intercalações de arenitos com estratificação plano-paralela (interdunas secas) (Assine et al., 2004); (IPT, 1981). Os arenitos da Formação Botucatu representam o principal reservatório do $\mathrm{SAG}$, devido às características dos sedimentos, os quais apresentam grande quantidade de poros interconectados, com elevada capacidade de armazenamento e transmissibilidade de água, conferindo ao sistema ótima produtividade (Rocha, 1997). 


\section{MATERAIS E MÉTODOS}

\section{Técnica da Sondagem Elétrica Vertical}

A técnica de investigação da Sondagem Elétrica Vertical (SEV), desenvolvida a partir do método da eletrorresistividade (parâmetro obtido: resistividade elétrica), possibilita a identificação litológica dos diferentes materiais geológicos em subsuperfície e ainda caracteriza seus estados em termos de alteração, fraturamento e saturação (Braga, 2016).

Esta técnica, desenvolvida com o arranjo
Schlumberger, consiste em uma sucessão de medidas da resistividade, efetuadas a partir da superfície do terreno, mantendo-se separação crescente entre os eletrodos de emissão de corrente $(\mathrm{AB})$.

Os eletrodos são alinhados na superfície do terreno de maneira simétrica, e durante as medidas, a direção do arranjo e o centro do dipolo de recepção de potencial permanecem fixos (Figura 4).

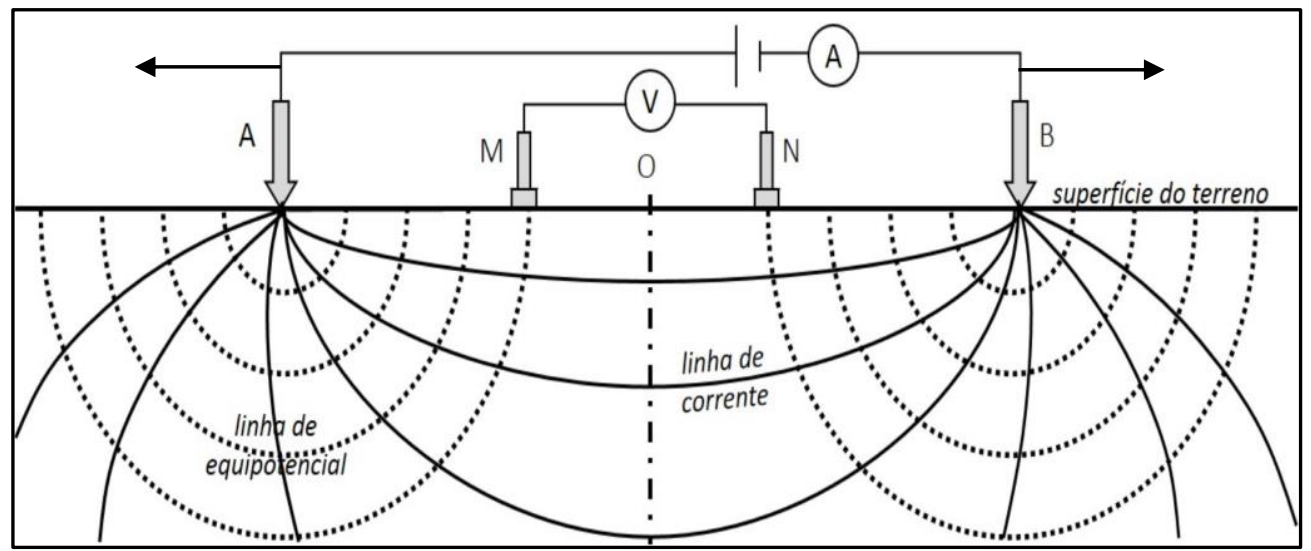

Figura 4. Esquema das medições de campo da técnica da SEV - arranjo Schlumberger.

No desenvolvimento da SEV - arranjo Schlumberger, a corrente elétrica (I) ao ser introduzida no subsolo por meio dos eletrodos $\mathrm{A}$ e $\mathrm{B}$, resulta que entre os eletrodos $\mathrm{M}$ e $\mathrm{N}$ medese a diferença de potencial $(\Delta \mathrm{V})$ gerada. As medidas obtidas, juntamente com o coeficiente geométrico $(\pi)$ relativo aos espaçamentos AMNB utilizados, permitem o cálculo da resistividade aparente $\left(\rho_{a}\right)$ - medida referente ao meio geológico não homogêneo - utilizando-se a Equação 1:

$\rho_{\mathrm{a}}=\left[\frac{\pi \cdot(\overline{\mathrm{AM}} \cdot \overline{\mathrm{AN}})}{\overline{\mathrm{MN}}}\right] \cdot \frac{\Delta \mathrm{V}}{\mathrm{I}}$

Ao aumentar-se a distância entre os eletrodos de corrente $\mathrm{AB}$, o volume total da subsuperfície incluída na medida também aumenta, permitindo alcançar camadas cada vez mais profundas. A profundidade teórica atingida pode ser tomada pela relação $\mathrm{AB} / 4$ (Orellana, 1972). Os resultados estarão, portanto, estritamente ligados a variações da resistividade com a profundidade.

\section{Parâmetro de Dar Zarrouk - Condutância Longitudinal Unitária}

Nas discussões teóricas sobre os meios condutores estratificados, determinados parâmetros têm fundamental importância na interpretação e entendimento do modelo geoelétrico para uma determinada situação geológica. Tais parâmetros resultam de uma combinação, por meio de multiplicação ou divisão, da espessura e resistividade de cada camada geoelétrica obtida no modelo, tendo sido denominados de parâmetros de Dar Zarrouk (Maillet, 1947).

Considerando uma seção geoelétrica, onde $\rho_{\mathrm{i}}$ é a resistividade $(\Omega . m)$ e $E_{i}$ a espessura $(m)$ da camada, a corrente elétrica ao fluir no subsolo pode seguir dois caminhos preferenciais: um perpendicular e outro paralelo à estratificação (Henriet, 1975); (Casas et al., 2008); Sendròs et al. (2014); (Braga, 2016); Gemail et al. (2017). No fluxo de corrente paralelo à estratificação, a resistência da camada $\boldsymbol{i}$ será dada pela Equação 2.

$$
\mathrm{R}_{\mathrm{i}}=\rho_{i} \frac{\mathrm{L}}{\mathrm{S}}=\rho_{i} \frac{1}{\mathrm{E}_{\mathrm{i}} \times 1}=\frac{\rho_{i}}{\mathrm{E}_{\mathrm{i}}}
$$

Como as resistências elétricas das camadas geoelétricas estão dispostas em arranjo paralelo, não se pode somá-las. Por isso, o cálculo deve ser efetuado a partir da soma dos seus inversos, uma vez que esta é a operação que permite obter 
a resistência resultante. O quociente obtido é denominado de condutância longitudinal unitária $\left(S_{i}\right)$ (Equação 3), cujas dimensões são expressas em siemens ou $\left(\Omega^{-1}\right)$. O conjunto das $n$ camadas da seção resultará na condutância longitudinal total (S) (Equação 4).

$$
\mathrm{S}_{\mathrm{i}}=\frac{\mathrm{E}_{\mathrm{i}}}{\rho_{\mathrm{i}}} \quad \text { (3) } \quad \mathrm{S}=\sum_{\mathrm{i}-1}^{\mathrm{n}} \frac{\mathrm{E}_{\mathrm{i}}}{\rho_{\mathrm{i}}}
$$

\section{Aquisição dos Dados}

Os ensaios geofísicos utilizados neste trabalho foram desenvolvidos pelo IPT, nas décadas de 70 e 80, atendendo às solicitações do Consórcio Paulipetro, com o intuito de investigar regionalmente a litoestratigrafia da bacia do Paraná, nas regiões sul e sudeste do Brasil. A Figura 5 apresenta alocalização das Sondagens Elétricas Verticais (SEVs) executadas, inclusive os poços tubulares considerados para a geração dos mapas temáticos.

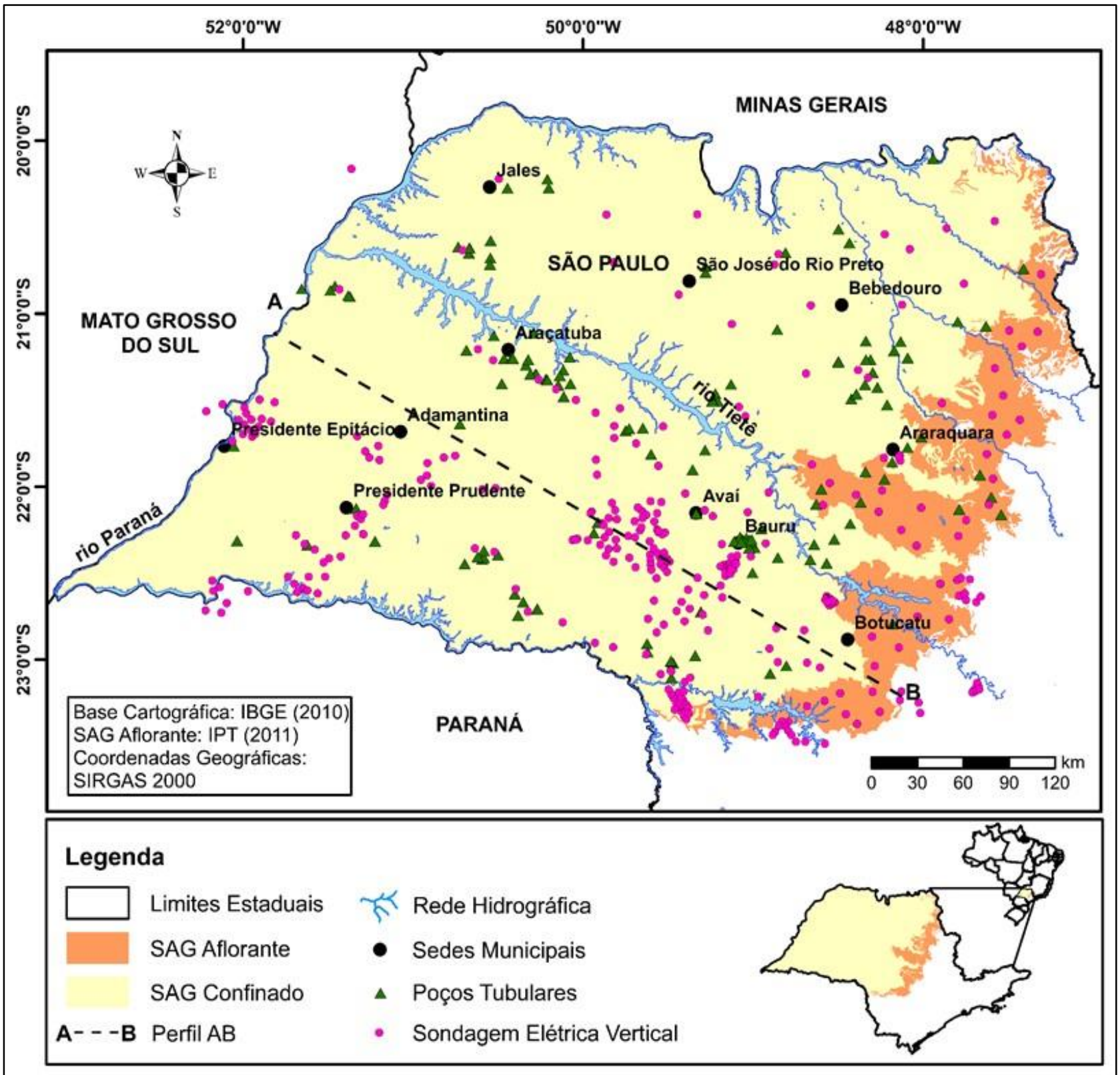

Figura 5 - Mapa de localização dos ensaios geofísicos executados e poços tubulares compilados.

Foram utilizadas 293 SEVs neste trabalho, as quais foram coletadas a partir do desenvolvimento do projeto de pesquisa realizado pelo IPT \& Unesp (2013). O enfoque principal deste projeto foi a recuperação, digitalização e reinterpretação das SEVs, executadas com arranjo de eletrodos

\section{Schlumberger.}

A realização destas SEVs teve como objetivos principais delimitar o contato BauruBasalto e estimar a espessura da Formação Serra Geral (contato Basalto-Botucatu).

A integração entre dados geológicos e geofísicos viabilizou a detecção de possíveis 
anomalias estruturais, bem como a configuração da geometria dos aquíferos existentes em áreas previamente selecionadas e a definição da profundidade ao topo do embasamento cristalino da bacia sedimentar.

As sondagens elétricas verticais executadas permitiram atingir grandes profundidades teóricas de investigação, em torno de $5.500 \mathrm{~m}$ em alguns locais (Tabela 1), com AB/2 máximo igual a $11.000 \mathrm{~m}$, espaçamento facilmente atingido na época a partir da realização de SEVs (Paulipetro, 1981).

Dessa maneira, a utilização destes dados geofísicos possibilitou a investigação do comportamento estrutural da Bacia Sedimentar do Paraná, inclusive estimar a vulnerabilidade natural do SAG, principalmente em áreas centrais da bacia, visto que as grandes profundidades destes locais dificultam a aplicação de técnicas de investigação diretas.

Tabela 1 - Variação nos valores obtidos - SEVs.

\begin{tabular}{|c|c|c|c|c|c|c|c|}
\hline \multicolumn{8}{|c|}{ Dados Gerais das SEVs } \\
\hline \multicolumn{2}{|c|}{ Cota aproximada (m) } & \multicolumn{2}{|c|}{$\mathrm{AB} / 2$ máximo $(\mathrm{m})$} & \multicolumn{3}{|c|}{ Profundidade do NA (m) } & Cota do NA (m) \\
\hline \multicolumn{2}{|c|}{255,0 a 890,0} & \multicolumn{2}{|l|}{400 a 11.000} & \multicolumn{2}{|r|}{0,9 a 83,5} & \multicolumn{2}{|c|}{233,0 a 881,7} \\
\hline \multicolumn{8}{|c|}{ Basalto - Formação Serra Geral } \\
\hline $\begin{array}{l}\text { Profundidade } \\
\text { ao Topo }(\mathrm{m})\end{array}$ & $\begin{array}{l}\text { Cota do } \\
\text { Topo }(\mathrm{m})\end{array}$ & $\begin{array}{c}\text { Resistividade } \\
\text { Derrame } 1 \\
(\Omega . \mathrm{m})\end{array}$ & $\begin{array}{r}\text { Resisti } \\
\text { Derra } \\
(\Omega\end{array}$ & $\begin{array}{l}\text { dade } \\
\text { e } 2 \\
\end{array}$ & $\begin{array}{c}\text { Espessura } \\
\text { Derrame } 1 \\
(\mathrm{~m})\end{array}$ & $\begin{array}{c}\text { Espessura } \\
\text { Derrame } 2 \\
(\mathrm{~m})\end{array}$ & $\begin{array}{l}\text { Espessura } \\
\text { Total }(\mathrm{m})\end{array}$ \\
\hline 0,0 a 585,1 & $\begin{array}{c}-12,0 \mathrm{a} \\
881,7 \\
\end{array}$ & 28,0 a 350,0 & 80,0 a & 293,0 & 33,6 a 566,9 & $\begin{array}{c}0,0 \mathrm{a} \\
1.438,1 \\
\end{array}$ & 0,0 a $1.438,1$ \\
\hline \multicolumn{4}{|c|}{ Formação Botucatu } & \multicolumn{4}{|c|}{ Embasamento Cristalino } \\
\hline \multicolumn{2}{|c|}{$\begin{array}{r}\text { Profundidade } \\
\text { ao Topo }(\mathrm{m}) \\
\end{array}$} & \multirow{2}{*}{\multicolumn{2}{|c|}{$\begin{array}{c}\text { Cota do Topo }(\mathrm{m}) \\
-1.394,9 \text { a } 874,9\end{array}$}} & & $\begin{array}{c}\text { Profundidade } \\
\text { ao Topo }(\mathrm{m}) \\
\end{array}$ & & Cota do Topo (m) \\
\hline \multicolumn{2}{|c|}{10,8 a $1.775,0$} & & & & 509,7 a $4.161,4$ & & $-3.621,4$ a 50,1 \\
\hline
\end{tabular}

Os dados de poços tubulares coletados integram o acervo de informações utilizadas no projeto, tendo como fonte o Sistema de Informações de Águas Subterrâneas (SIAGAS), disponibilizado pelo Serviço Geológico do
Brasil (CPRM, 2015). Procurou-se selecionar poços confiáveis com informações sobre a estratigrafia da bacia. Ao todo, foram utilizados 179 poços tubulares, cujas principais informações são apresentadas na Tabela 2.

Tabela 2 - Variação nos valores obtidos em poços cadastrados.

\begin{tabular}{c|c|c}
\hline \multicolumn{3}{c}{ Basalto - Formação Serra Geral } \\
\hline Profundidade ao Topo $(\mathrm{m})$ & Cota do Topo $(\mathrm{m})$ & Espessura Total $(\mathrm{m})$ \\
\hline 0 a 251 & 0 a 679 & 0 a 1.537 \\
\hline \multicolumn{3}{c}{ Formação Botucatu } \\
\hline Profundidade ao Topo $(\mathrm{m})$ & Cota do Topo $(\mathrm{m})$ \\
\hline 52 a 1.730 & -1.431 a 870 \\
\hline \multicolumn{3}{c}{ Embasamento Cristalino } \\
\hline Profundidade ao Topo $(\mathrm{m})$ & Cota do Topo $(\mathrm{m})$ \\
\hline
\end{tabular}

\section{Sistematização e Processamento dos Dados}

$\mathrm{Na}$ etapa de sistematização e processamento dos dados, foram empregados os softwares Microsoft Excel (Microsoft Corporation, 2007), para a organização das informações e cálculo de variáveis relativas às SEVs; e o IX1D (Interpex Limited, 2008), utilizado para o processamento das SEVs e refinamento dos modelos geoelétricos produzidos pelo IPT, nas décadas de 1970 e 1980.

Os mapas temáticos de interesse foram gerados pelo software Surfer 8.0 (Golden Software Inc., 2002), utilizando o interpolador Natural Neighbor. A elaboração dos layouts finais dos mapas temáticos foi realizada em ambiente SIG ArcGIS 10.1 (ESRI, 2012). 


\section{RESULTADOS}

Modelo Geoelétrico e Contorno Estrutural

A figura 6 apresenta duas SEVs típicas para a área estudada, nas quais são apresentados os dados de campo, a curva ajustada a partir da inversão destes dados e o modelo geoelétrico resultante do processamento. Este modelo geoelétrico apresenta as espessuras e resistividades das camadas geoelétricas.

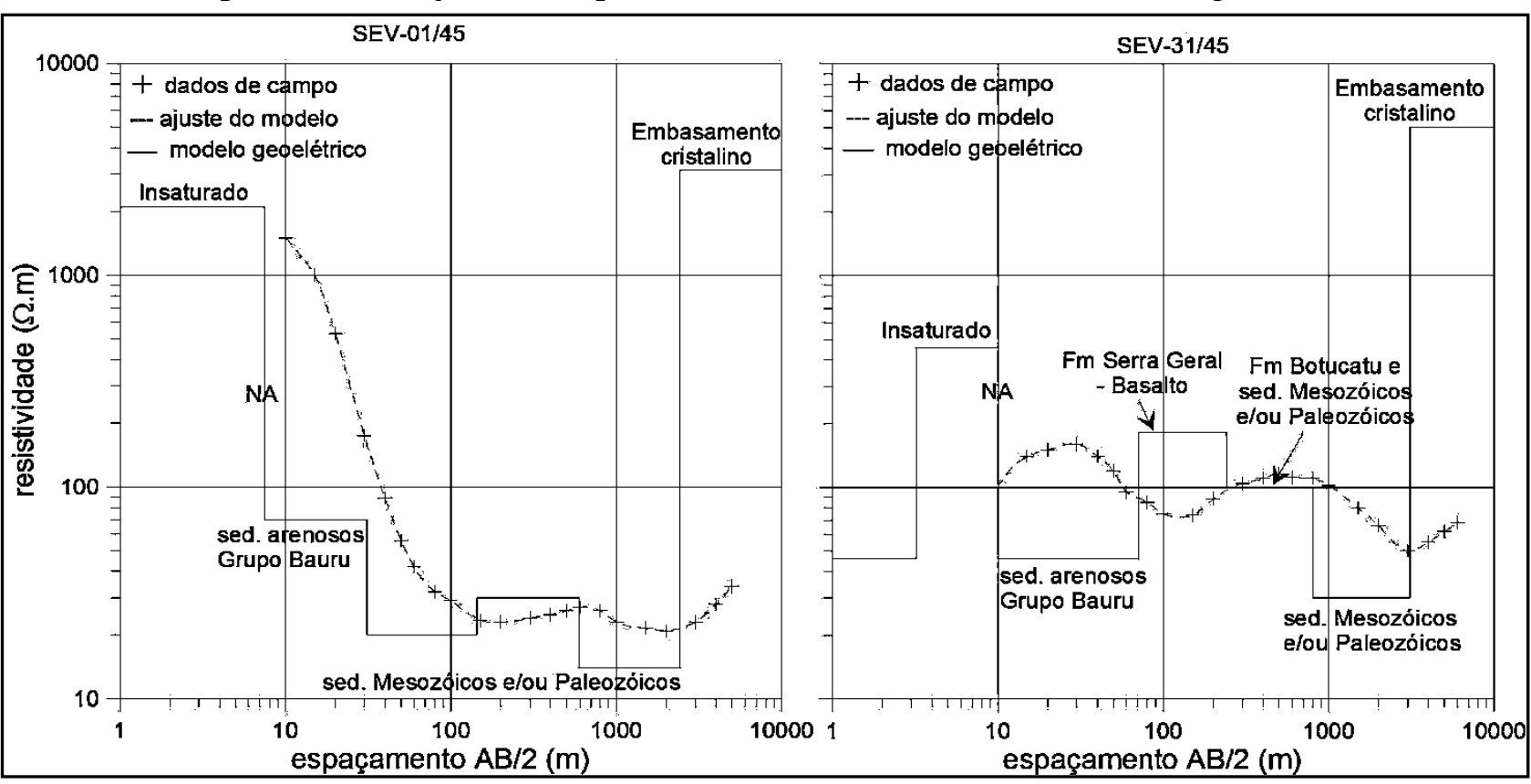

Figura 6 - Padrão das SEVs - curva de campo e modelo geoelétrico.

Na SEV-01/45, não ocorre a Formação Serra Geral - basaltos, sendo que os sedimentos superficiais (Grupo Bauru) estão em contato direto com a Formação Botucatu e demais formações da estratigrafia da bacia. Na SEV31/45, a ocorrência da Formação Serra Geral é nítida nos dados de campo, determinando com precisão sua espessura e o topo da Formação Botucatu.

Para os basaltos da Formação Serra Geral, as SEVs apresentaram valores da profundidade ao topo variando de 0 a 585,1 metros, com variação da espessura total entre 0 e $1.438,1$ metros. A partir do mapa de isópacas (Figura 7), fica evidente a região aproximada de não ocorrência dos basaltos, apresentando uma tendência de aumento de espessura a partir deste local, com um contato brusco nos seus limites.

Tal região está situada no município de Piratininga/SP, à sudoeste de Bauru/SP, onde ocorre uma estrutura dômica caracterizada por um alto estrutural representado por um horst limitado por falhas N40-60E, onde há exposição das formações Pirambóia e Corumbataí, nos domínios das unidades cretáceas da bacia do Paraná, Grupo Bauru (Campos et al., 2008).

De acordo com o processamento e reinterpretação das SEVs, foram identificadas áreas onde ocorreram dois ou apenas um derrame basáltico, ao longo do processo de estruturação e evolução da bacia sedimentar. Para o derrame 1, foram determinadas resistividades entre 28 e $350 \Omega$.m, com espessuras variando de 33,6 a 566,9 metros. Quanto ao derrame 2, as resistividades estão entre 80 e $3.293 \Omega . m$.

Os valores de resistividade elétrica de até 150 $\Omega . \mathrm{m}$ foram considerados como sendo característicos de rochas fraturadas e/ou mais porosas. A Figura 8 apresenta o mapa de resistividade elétrica para os basaltos do derrame 2. A Figura 9 representa o mapa de contorno estrutural da cota do topo dos basaltos, que mostra uma variação nos valores de -12 a 881,7 metros e uma tendência de mergulho com sentido NW. A profundidade ao topo da Formação Botucatu apresentou uma variação de 10,8 a 1.775 metros. As cotas do topo destes sedimentos variaram de $-1.394,9$ a 874,9 metros, com um mergulho preferencial no sentido $\mathrm{W}$ (Figura 10). A leste, essas rochas tendem a um soerguimento, localizando-se a pouca profundidade, cujo afloramento ocorre nas áreas de recarga direta do SAG. 


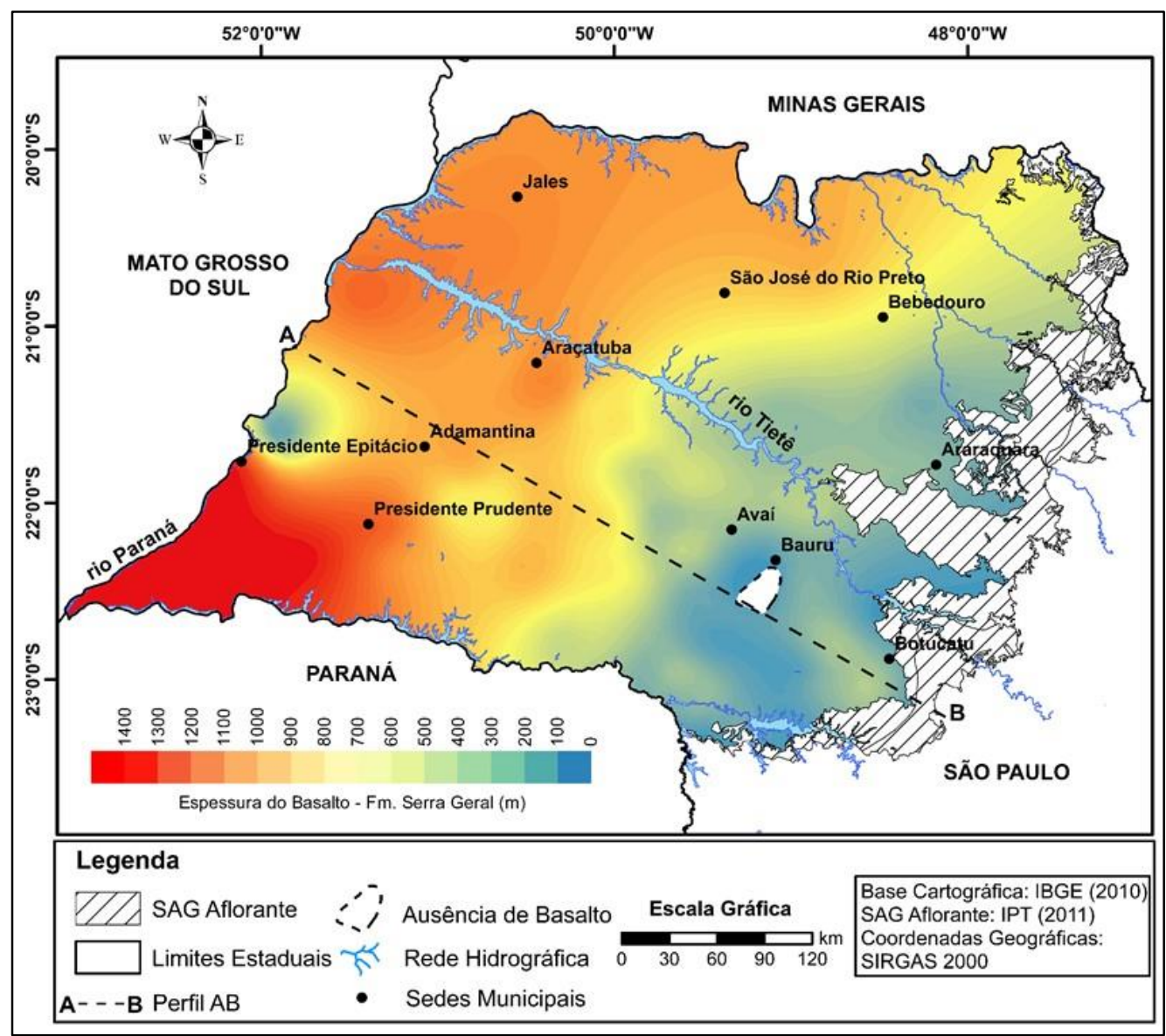

Figura 7 - Mapa de isópacas dos basaltos - Formação Serra Geral.

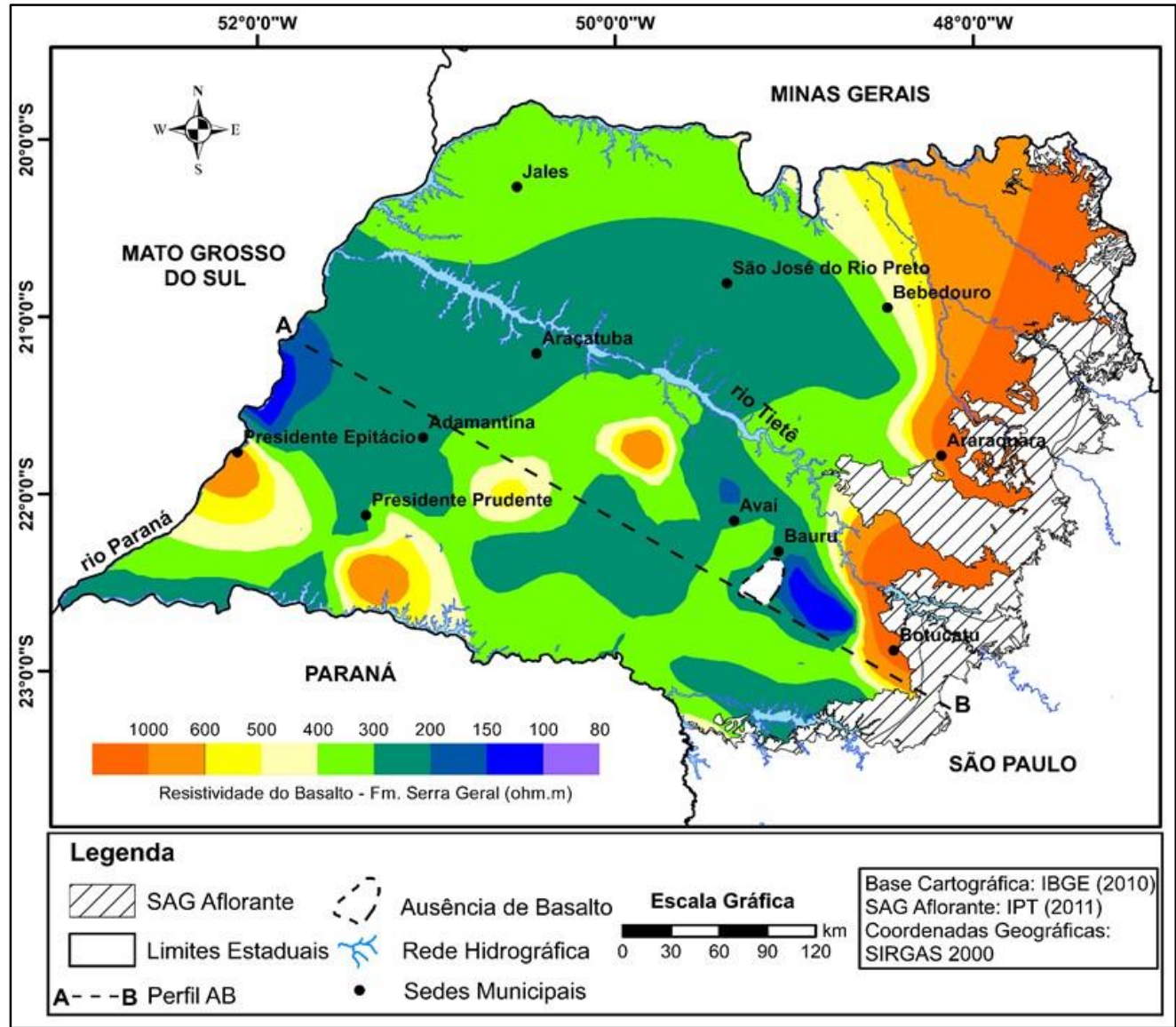

Figura 8 - Mapa de resistividade elétrica dos basaltos - Formação Serra Geral. 


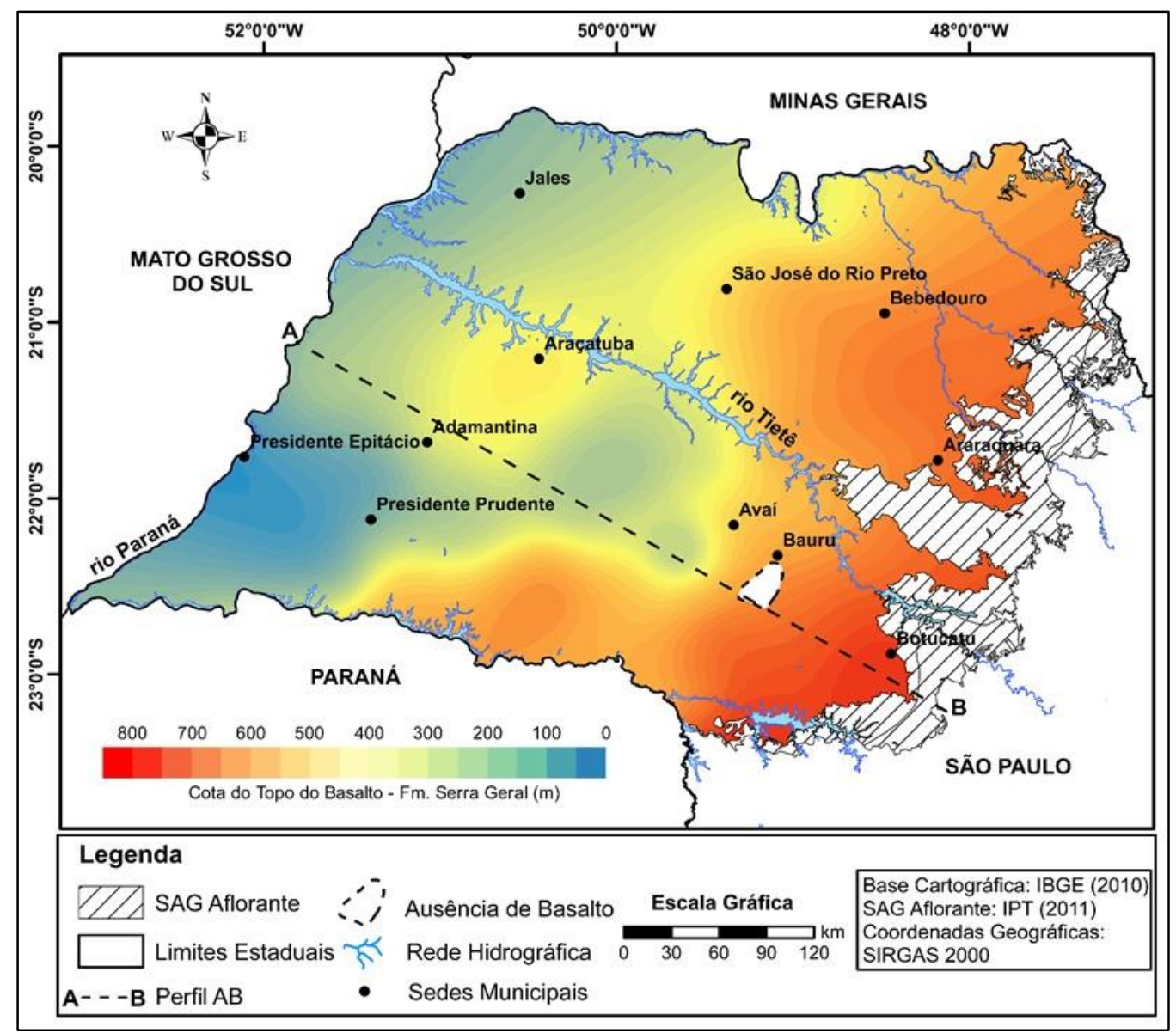

Figura 9 - Mapa de contorno estrutural dos basaltos - Formação Serra Geral.

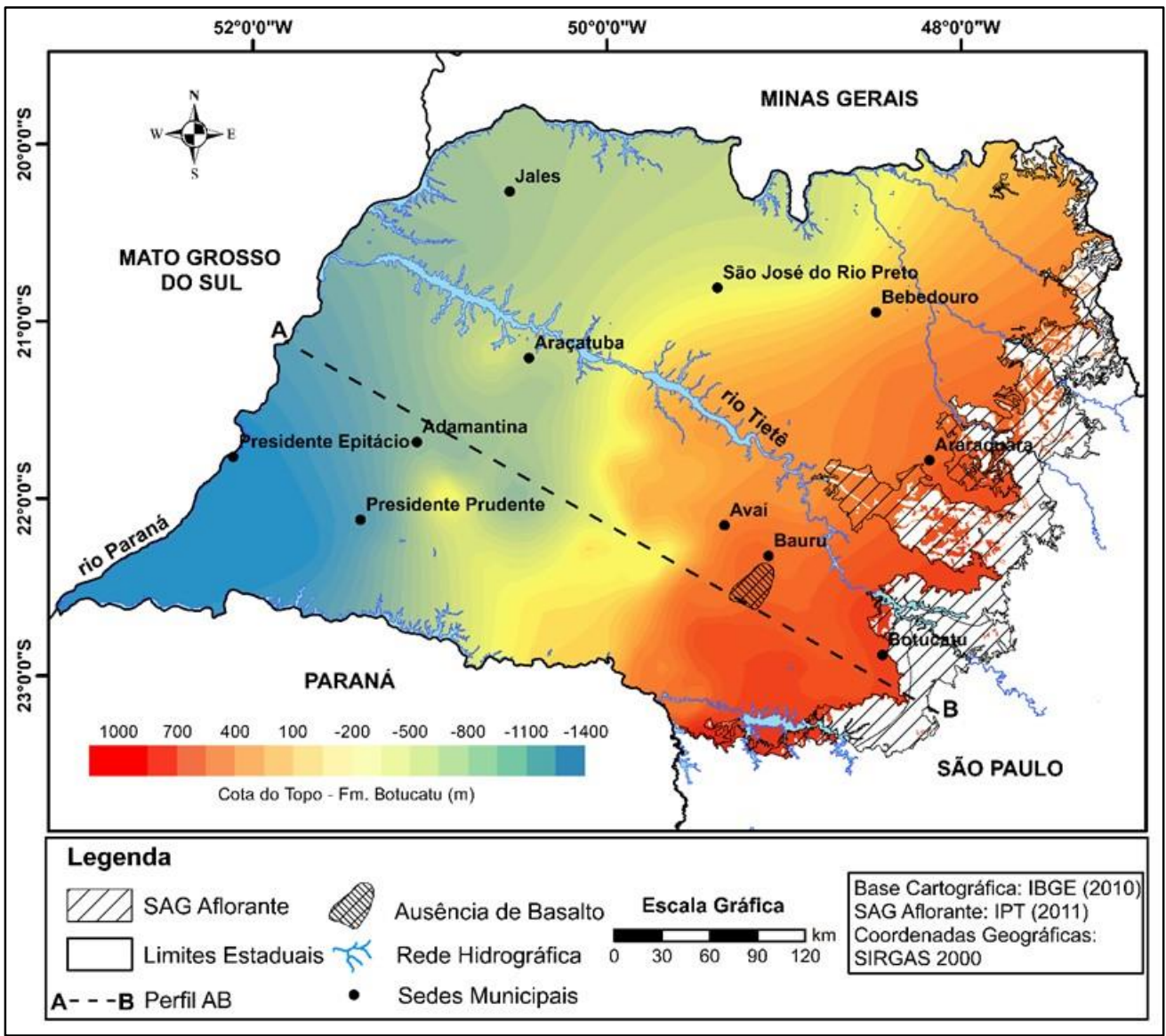

Figura 10 - Mapa de contorno estrutural da Formação Botucatu. 


\section{Vulnerabilidade Natural do Sistema Aquífero Guarani (SAG)}

$\mathrm{Na}$ estimativa da vulnerabilidade natural, foi necessário considerar todo o pacote de rochas sobrepostas ao SAG confinado, inclusive os sedimentos em sua área de afloramento. Portanto, devido às características geológicas, as rochas foram individualizadas em dois grupos: (1) Sedimentos do Grupo Bauru e da área de afloramento do SAG; e (2) Basaltos - Fm. Serra Geral (Tabela 3). Com base nesta subdivisão, foram propostas faixas de variação para a condutância longitudinal de rochas sedimentares e vulcânicas (Tabela 4).

Tabela 3 - Modelo geral da condutância longitudinal (S).

\begin{tabular}{c|c|c|c}
\hline & $\begin{array}{c}\text { Resistividade } \\
(\mathbf{\Omega . m})\end{array}$ & $\begin{array}{c}\text { Espessura } \\
(\mathbf{m})\end{array}$ & $\begin{array}{c}\text { Condutância } \\
\text { Longitudinal }(\mathbf{S})\end{array}$ \\
\hline $\begin{array}{c}\text { Sedimentos do Grupo Bauru e da } \\
\text { área de afloramento do SAG - S }\end{array}$ & 3,0 a 300,0 & 0,0 a 585,0 & 0,001 a 22,53 \\
\hline Basaltos - Fm. Serra Geral - S $\mathbf{S}_{\mathbf{2}}$ & 80,0 a $3.293,0$ & 0,0 a $1.438,0$ & 0,006 a 6,06 \\
\hline
\end{tabular}

Tabela 4 - Faixas de variação da condutância longitudinal - rochas sedimentares e vulcânicas.

\begin{tabular}{|c|c|c|c|c|c|c|}
\hline \multirow{2}{*}{$\begin{array}{c}\text { Classes de } \\
\text { Vulnerabilidade }\end{array}$} & \multicolumn{3}{|c|}{$\begin{array}{c}\text { Condutância Longitudinal das Rochas } \\
\text { Sedimentares }-S_{1}\end{array}$} & \multicolumn{3}{|c|}{$\begin{array}{c}\text { Condutância Longitudinal das Rochas } \\
\text { Vulcânicas (Basalto) }-S_{2} \\
\end{array}$} \\
\hline & $\rho(\Omega . m)$ & $\mathbf{E}(\mathbf{m})$ & $\mathrm{S}_{1}$ (siemens) & $\rho(\Omega . \mathrm{m})$ & $\mathbf{E}(\mathbf{m})$ & $\mathbf{S}_{2}$ (siemens) \\
\hline Muito Baixa & $<10$ & $>300$ & $>30,0$ & 500 a 1.000 & $>2.000$ & $>4,0$ \\
\hline Baixa & 10 a 20 & 200 a 300 & 10,0 a 30,0 & 200 a 500 & 400 a 2.000 & 2,0 a 4,0 \\
\hline Moderada & 20 a 40 & 120 a 200 & 3,0 a 10,0 & 100 a 200 & 150 a 400 & 1,5 a 2,0 \\
\hline Alta & 40 a 80 & 80 a 120 & 1,0 a 3,0 & 60 a 100 & 50 a 150 & 0,8 a 1,5 \\
\hline Muito Alta & 80 a 120 & 30 a 80 & 0,3 a 1,0 & 20 a 60 & 8 a 50 & 0,4 a 0,8 \\
\hline Extrema & 120 a 300 & $<30$ & $<0,3$ & $<20$ & $<8$ & $<0,4$ \\
\hline
\end{tabular}

Legenda: $\rho=$ resistividade; $\mathrm{E}=$ espessura; $\mathrm{S}_{1}=$ condutância longitudinal dos sedimentos; $\mathrm{S}_{2}=$ condutância longitudinal dos basaltos.

Para os sedimentos do Grupo Bauru e da área de afloramento do SAG, resistividades de 120 a $300 \Omega . m$ e espessuras inferiores a 30 metros resultam em valores de condutância longitudinal menores do que 0,3 siemens, o que confere vulnerabilidade natural extrema às águas subterrâneas. Em contrapartida, sedimentos com resistividades menores do que $10 \Omega . \mathrm{m}$ e espessuras superiores a 300 metros apresentam valores de condutância longitudinal superiores a 30 siemens, permitindo atribuir vulnerabilidade muito baixa ao SAG.

Com relação às rochas vulcânicas da Formação Serra Geral, resistividades inferiores a $20 \Omega . m$ representam basaltos bastante fraturados e/ou porosos, que associadas a espessuras menores do que 8 metros, resultam em valores de condutância longitudinal inferiores a 0,4 siemens.

Nesta situação, a vulnerabilidade à contaminação do aquífero é extrema. Entretanto, basaltos com resistividades de 500 a $1.000 \Omega . m$ (baixo grau de alteração e/ou menor porosidade) e bastantes espessos (maiores do que 2.000 metros) apresentam condutância longitudinal superior a 4 siemens, o que resulta em vulnerabilidade muito baixa à contaminação.

Partindo do conceito da condutância longitudinal unitária $\left(\mathrm{S}_{\mathrm{i}}\right)$, a vulnerabilidade natural do SAG foi obtida por meio da soma entre $S_{1}$ (sedimentos do Grupo Bauru e da área de afloramento do SAG) e $\mathrm{S}_{2}$ (basaltos Serra Geral), obtendo-se as classes de vulnerabilidade apresentadas na Tabela 5.

Tabela 5 - Vulnerabilidade Natural do Sistema Aquífero Guarani - SAG.

\begin{tabular}{c|c|c|c}
\hline \multirow{2}{*}{$\begin{array}{c}\text { Uso e Ocupação do } \\
\text { Solo }\end{array}$} & \multicolumn{2}{|c|}{ Vulnerabilidade Natural } & \multirow{2}{*}{$\begin{array}{c}\text { Condutância } \\
\text { Longitudinal (siemens) }\end{array}$} \\
\cline { 2 - 3 } Sem Restrições & Interpretação & Classes & $>34,0$ \\
\hline \multirow{2}{*}{ Pouco Vulnerável } & Muito Baixa & 12,0 a 34,0 \\
\cline { 3 - 3 } & & Baixa & 4,5 a 12,0 \\
\hline \multirow{2}{*}{$\begin{array}{c}\text { Com Restrições } \\
\text { Restrições }\end{array}$} & Vulnerável & Moderada & 1,8 a 4,5 \\
\cline { 3 - 3 } & \multirow{2}{*}{ Muito Vulnerável } & Alta & 0,7 a 1,8 \\
\cline { 3 - 3 } & & Muito Alta & $<0,7$ \\
\cline { 3 - 3 } & & Extrema & \\
\hline
\end{tabular}


Nesta proposta de classificação, valores de condutância longitudinal superiores a 12 siemens representam áreas do SAG pouco vulneráveis, inexistindo restrições quanto ao uso e ocupação do solo. Por outro lado, regiões que apresentam condutância longitudinal entre $0 \mathrm{e}$ 4,5 são muito vulneráveis à contaminação, o que impõe muitas restrições quanto à instalação de atividades ou empreendimentos com elevado potencial poluidor. Conforme mostra a Figura 11 , os valores de condutância longitudinal $\left(\mathrm{S}_{1}\right)$ dos sedimentos são maiores na porção central da área de estudo, indicando que, nesta região, o
SAG é menos vulnerável à contaminação. Isto se deve a grandes espessuras dos sedimentos no centro da bacia sedimentar, inclusive à existência de arenitos argilosos, com intensa cimentação e nódulos carbonáticos que reduzem a permeabilidade e a resistividade elétrica, sendo característicos das formações Adamantina e Marília pertencentes ao Grupo Bauru (Paula e Silva, 2003).

O mapa da figura 12 indica que a condutância longitudinal $\left(\mathrm{S}_{2}\right)$ dos basaltos da Fm. Serra Geral é mais baixa na parte sudeste da área de estudo, devido a menores espessuras dos basaltos.

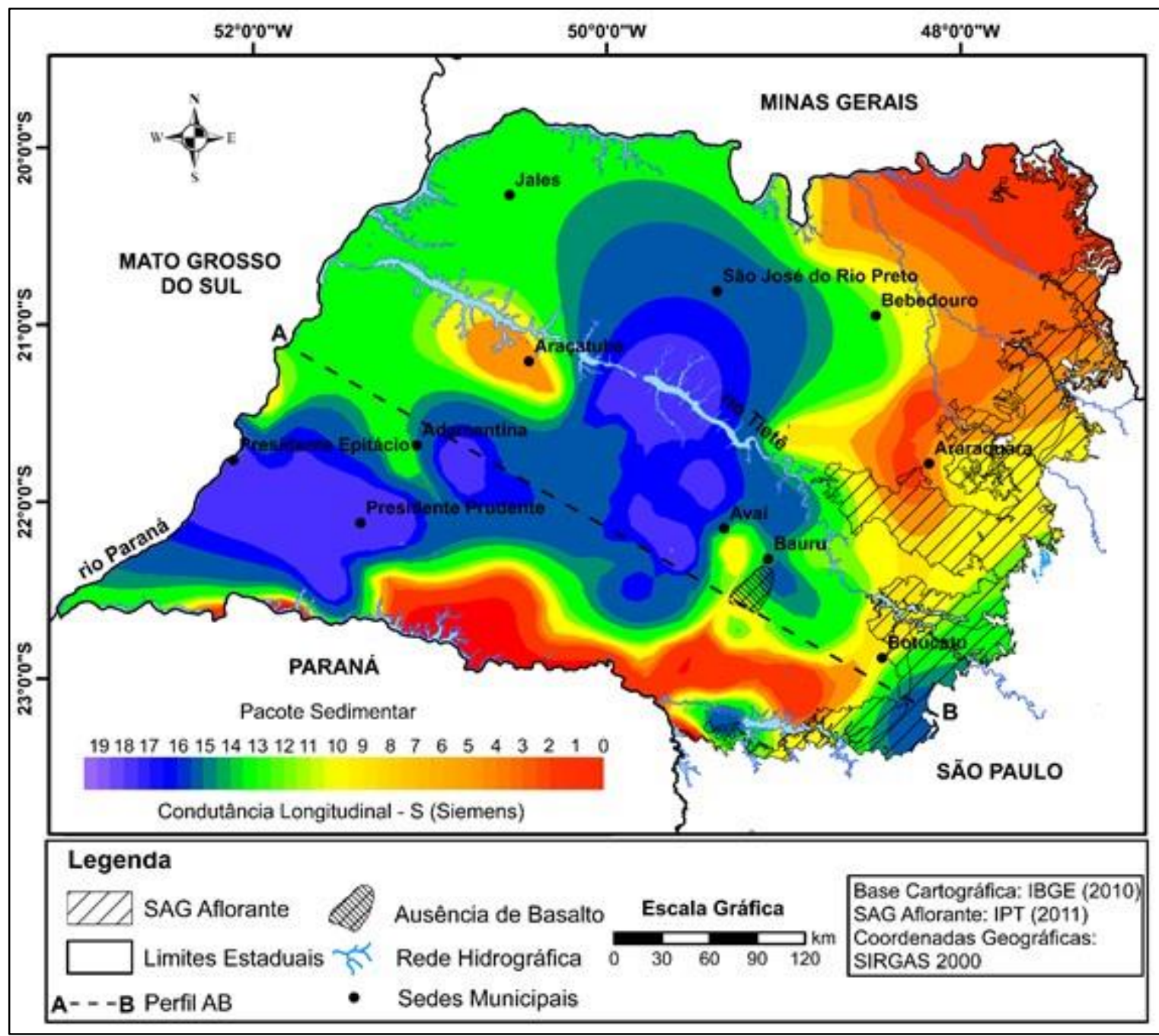

Figura 11 - Condutância longitudinal $\left(\mathrm{S}_{1}\right)$ dos sedimentos.

Na região central do domo de Piratininga, a não ocorrência de basaltos resulta em uma maior vulnerabilidade do SAG frente a contaminantes migrando verticalmente, a partir de camadas superficiais. A ausência destas rochas basálticas facilita o escoamento do contaminante, aumentando sua velocidade de percolação (Braga et al., 2016). O mapa de vulnerabilidade natural à contaminação do SAG é apresentado na figura 13.

Conforme o esperado, as regiões naturalmente mais vulneráveis concentram-se na área de afloramento do SAG. Nestas regiões, existem áreas de relevo plano e suave ondulado, sustentadas por espessos solos arenosos, muito friáveis, permeáveis e com baixa capacidade de retenção de poluentes (DAEE et al., 1984); (IPT, 2011). 


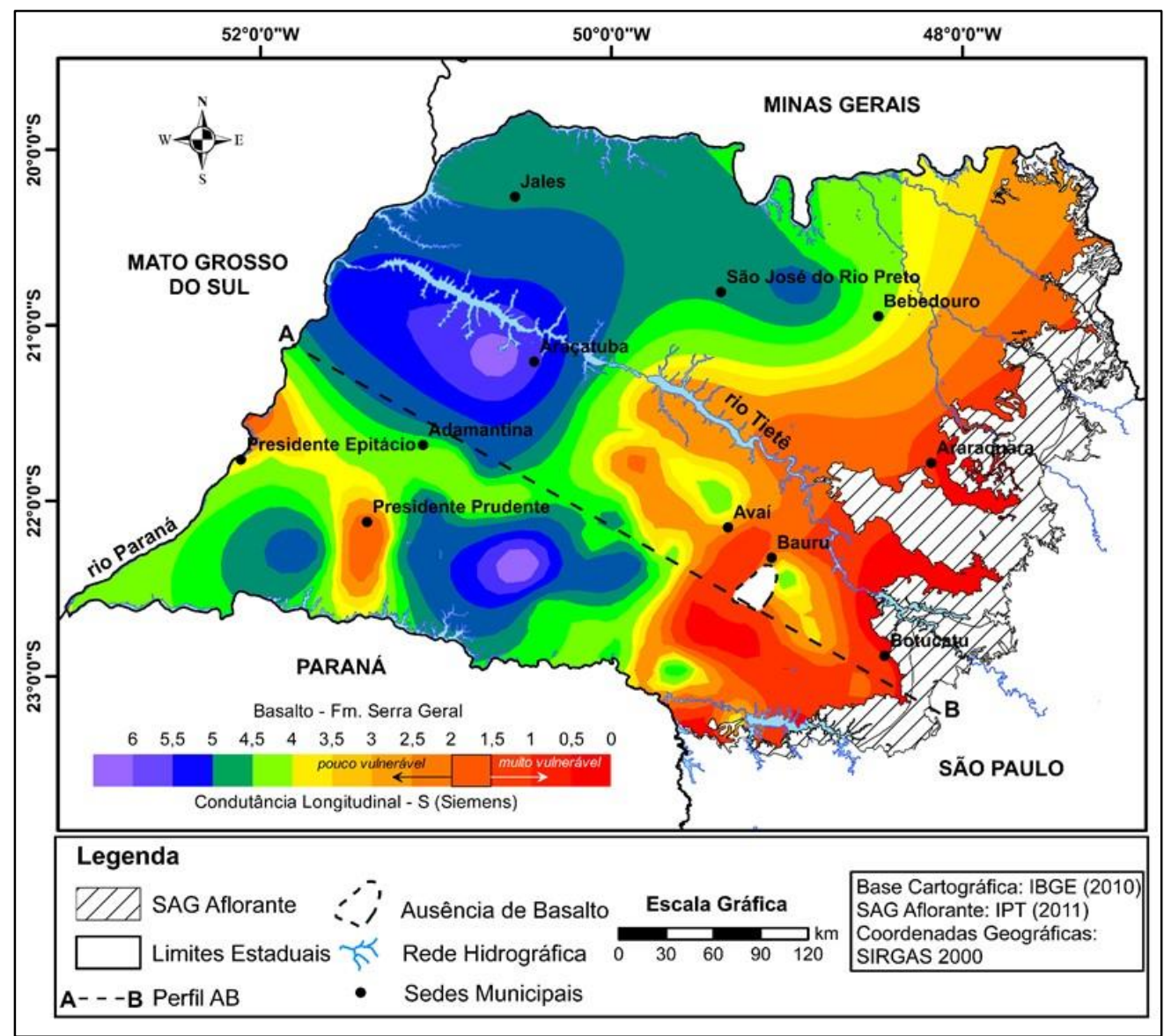

Figura 12 - Condutância longitudinal $\left(\mathrm{S}_{2}\right)$ dos basaltos.

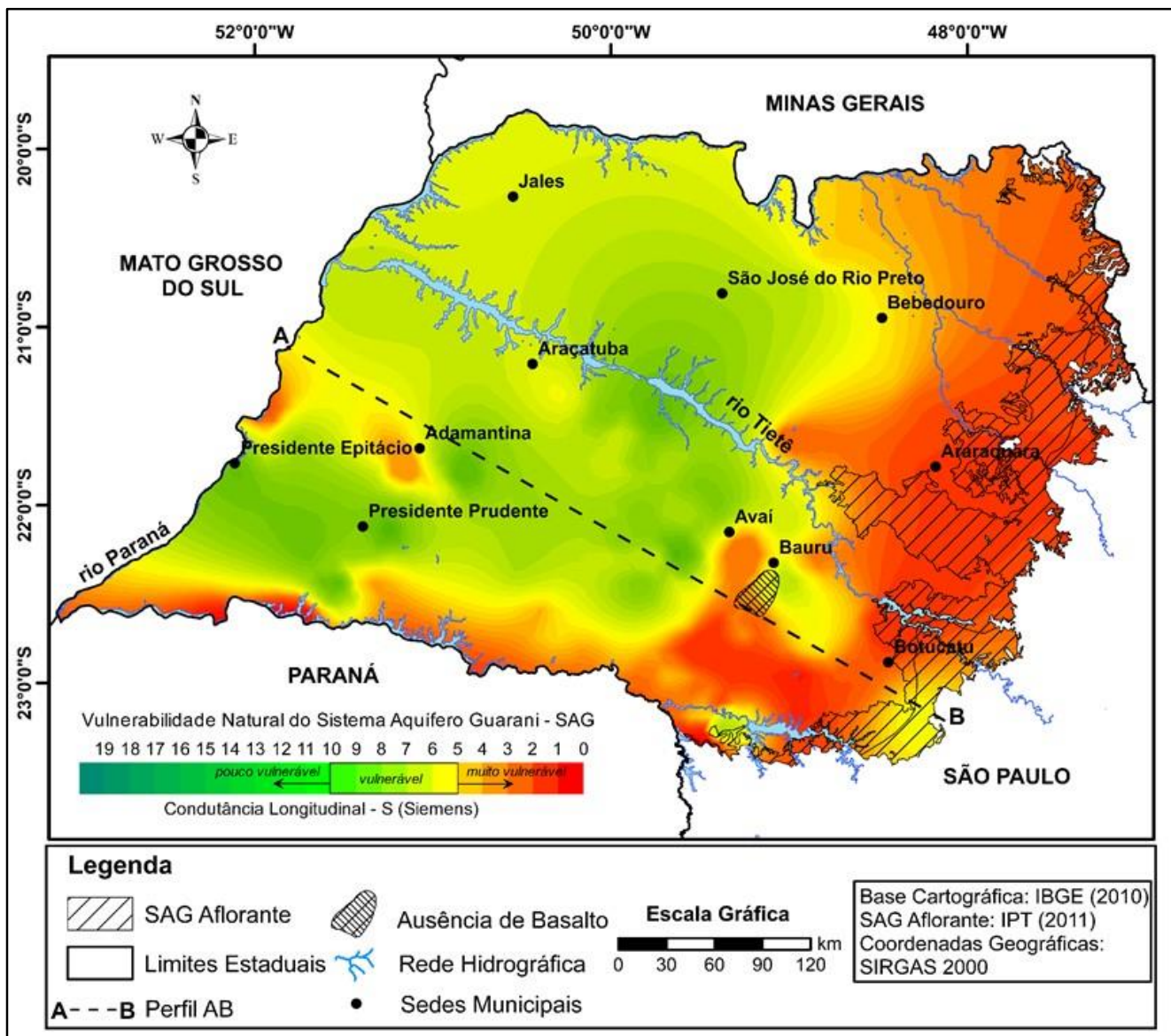

Figura 13 - Mapa de vulnerabilidade natural do Sistema Aquífero Guarani (SAG). 
Nas proximidades das bordas da bacia do Paraná, tanto as rochas sedimentares como as vulcânicas são menos espessas (Figura 14), como por exemplo a região do Domo de Piratininga, onde há uma área de não ocorrência de basaltos, o que torna o SAG ainda mais desprotegido. Desse modo, reduz-se a capacidade de atenuação (menor filtro) e, consequentemente, o tempo de trânsito dos contaminantes no percurso partindo da superfície topográfica em direção ao aquífero.

Naturalmente, áreas menos vulneráveis estão localizadas no centro da bacia (SAG confinado), devido a dois fatores: (1) grandes espessuras do pacote de rochas sobrepostas ao SAG; e (2) menores resistividades dos sedimentos Bauru (mais argilosos) e a presença de basaltos mais resistivos (menor permeabilidade), resultando no aumento da capacidade de retenção de poluentes.

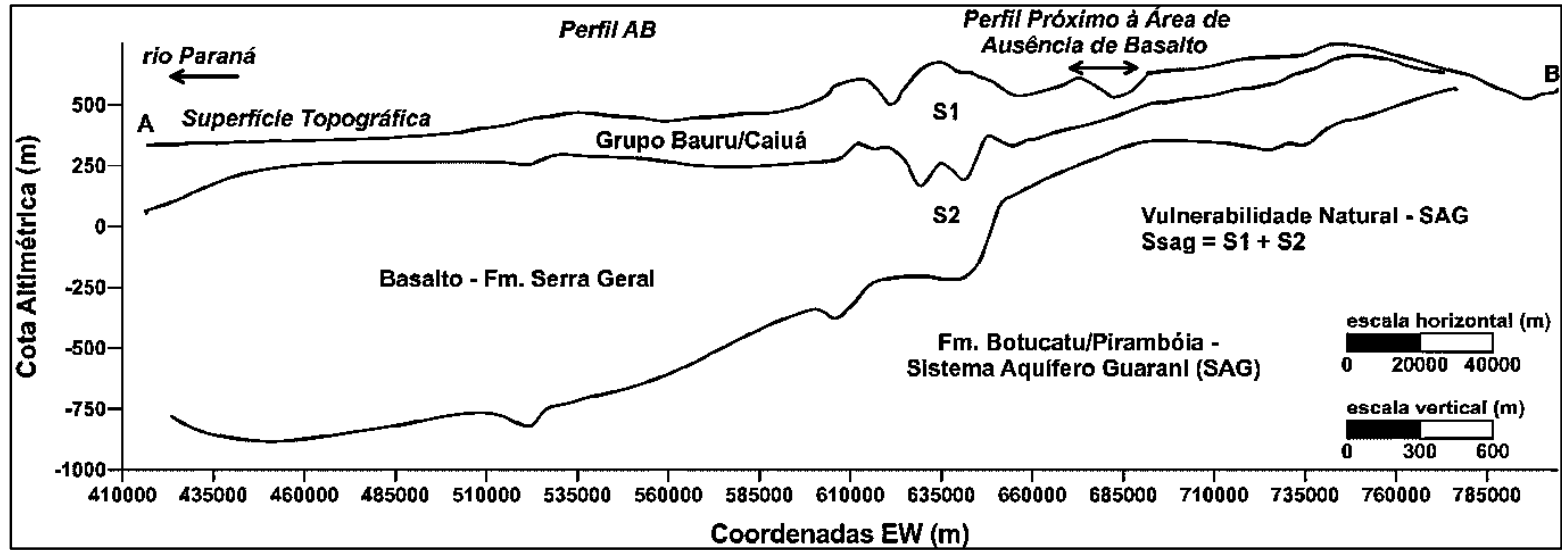

Figura 14 - Perfil AB.

\section{CONCLUSÕES}

As sondagens elétricas verticais - arranjo Schlumberger - apresentam bons resultados, considerando as medidas indiretas tomadas, para estudos rasos até grandes profundidades, como aquelas atingidas neste trabalho. De um modo geral, uma das grandes vantagens desta técnica é a capacidade de investigar várias litologias da bacia do Paraná sem a limitação de profundidades a serem alcançadas, podendo atingir litologias mais profundas como as rochas do Embasamento Cristalino. A precisão no processamento dos dados, através de softwares especializados, torna os modelos obtidos perfeitamente ajustáveis à litoestratigrafia local.

Os ensaios geofísicos aliados aos dados de poços tubulares permitiram estabelecer claramente as relações estratigráficas entre as camadas de rochas que se sobrepõem e constituem o SAG, considerando o contexto da Bacia Sedimentar do Paraná no Estado de São Paulo. O mapa de vulnerabilidade natural apresentou resultados robustos, indicando que as áreas mais vulneráveis estão situadas na área de afloramento do SAG, sendo que as regiões menos vulneráveis se concentram na porção central da bacia sedimentar (área de confinamento do SAG). É importante destacar que tais resultados devem ser considerados como uma avaliação para o reconhecimento preliminar da distribuição espacial da vulnerabilidade natural. Portanto, devem ser conduzidos estudos mais aprofundados, principalmente nas áreas mais vulneráveis do SAG.

A condutância longitudinal desponta como um parâmetro bastante promissor na estimativa da vulnerabilidade natural das águas subterrâneas, visto que permite uma avaliação rápida e precisa de áreas extensas como aquelas abrangidas pelo SAG, a partir de um número reduzido de fatores, algo muito interessante considerando o cenário de escassez de dados disponíveis em diversas regiões do Brasil. Portanto, este parâmetro geofísico pode ser empregado como uma alternativa aos modelos tradicionais para avaliação de vulnerabilidade natural, constituindo uma importante ferramenta para a proteção do SAG.

\section{AGRADECIMENTOS}

Os autores gostariam de agradecer ao Departamento de Geologia Aplicada, do Instituto de Geociências e Ciências Exatas - IGCE/UNESP e da Seção de Geotécnica, do Centro de Tecnologia 
de Obras de Infraestruturas, do Instituto de Pesquisas Tecnológicas do Estado de São Paulo - IPT, pela participação de alunos e pesquisadores e dados disponibilizados.

\section{REFERÊNCIAS}

AKPAN, A.E.; EBONG, E.D.; EMEKA, C.N. Exploratory assessment of groundwater vulnerability to pollution in Abi, southeastern Nigeria, using geophysical and geological techniques. Environmental Monitoring and Assessment, v. 187, n. 4, p. 1-18, 2015.

ALBUQUERQUE FILHO, J.L.; BARBOSA, M.C.; DE CARVALHO, A.M.; IKEMATSU, P.; CAVANI, A.C.M. Avaliação do perigo de contaminação do Sistema Aquífero Guarani em sua área de afloramento do Estado de São Paulo decorrente das atividades agrícolas. Águas Subterrâneas, v. 25, n. 1, p. 1-14, 2011.

ALLER, L.; BENNETT, T.; LEHR, J.H.; PETTY, R.J.; HACKETT, G. DRASTIC: a standardized system for evaluating groundwater pollution potential hydrogeologic setting. Environmental Protection Agency (EPA), Washington (DC), Report 600/2-87-035, 1987.

ARAÚJO, L.M.; FRANÇA, A.B.; POTTER, P.E. Hydrogeology of the Mercosul aquifer system in the Paraná and Chaco-Paraná Basins, South America, and comparison with the NavajoNugget aquifer system, USA. Hydrogeology Journal, v. 7, n. 3, p. 313-336, 1999.

ASSINE M.L., PIRANHA J.M., CARNEIRO C.D.R. Os paleodesertos Pirambóia e Botucatu. In: MANTESSO NETO, V.; BARTORELLI, A.; CARNEIRO, C.D.R.; BRITO NEVES, B.B. (org.). Geologia do continente sul-americano: evolução da obra de Fernando Flávio Marques de Almeida. São Paulo: Beca, p. 77-92, 2004.

BRAGA, A.C.O. Geofísica aplicada: métodos geoelétricos em hidrogeologia. 1. ed. São Paulo: Oficina de Textos, 160p., 2016.

BRAGA, A.C.O. \& FRANCISCO, R.F. Natural vulnerability assessment to contamination of unconfined aquifers by Longitudinal Conductance - (S) method. Journal of Geography and Geology, p. 68-79, 2014.

BRAGA, A.C.O.; MALAGUTTI FILHO, W.; DOURADO, J.C. Resistivity (DC) method applied to aquifer protection studies. Revista Brasileira de Geofísica, p. 573-581, 2006.

BRAGA, A.C.O.; BIRELLI, C.A.; BLANCO, R.G.; DOURADO, J.C.; FRANCISCO, R.F. Geofísica aplicada no controle estrutural na área do domo de Piratininga (SP). Geociências, v. 35, n. 4, p. 598-608, 2016.

CAETANO-CHANG, M.R. A Formação Pirambóia no centro-leste do Estado de São Paulo. 1997. 196p. Tese (Livre Docência em Geologia) - Instituto de Geociências e Ciências Exatas, Universidade Estadual Paulista, Rio Claro, 1997.

CAMPOS, A.F.; ROSTIROLLA, S.P.; BARTOSZECK, M.K.; ROMEIRO, A.T.; FERREIRA, F.J.F.; KIANG, C.H. Correlação de dados sísmicos multiescala e integração com arcabouço tectônico regional: exemplo da área do Domo de Piratininga, SP. Revista Brasileira de Geociências, v. 38, p. 18-28, 2008.

CARNEIRO, C.D.R. \& OLIVEIRA, H.V.B. Modelos 3D do Aquífero Guarani da Bacia do Paraná para divulgação científica. In: CONGRESSO BRASILEIRO DE ÁGUAS SUBTERRÂANEAS, 15, 2008, Natal, 2008. Anais...São Paulo: Associação Brasileira de Águas Subterrâneas (ABAS), v. 22, p. 1-17, 2008.

CASAS, A.; DIAZ, Y.; FONT, X.; HIMI, M.; PINTO, V.; TAPIAS, J.C. Assessing aquifer vulnerability to pollutants by electrical resistivity tomography (ERT) at a nitrate vulnerable zone in NE Spain. Environmental Geology, v. 54, n. 3, p. 515-520, 2008.

CIVITA, M. \& DE MAIO, M. SINTACS: un sistema parametrico per la valutazione e la cartografia della vulnerabilità degli acquiferi all'inquinamento. Metodologia e automazione. Bologna: Pitagora, 1997. 191 p.
DEPARTAMENTO DE ÁGUAS E ENERGIA ELÉTRICADAEE; UNIVERSIDADE ESTADUAL PAULISTAUNESP; SECRETARIA DO MEIO AMBIENTE DO ESTADO DE SÃO PAULO-SMA. Mapa Geológico do Estado de São Paulo. Escala 1:250.000. São Paulo: DAEE, Unesp, SMA. 1984.

DEPARTAMENTO DE ÁGUAS E ENERGIA ELÉTRICADAEE; INSTITUTO DE PESQUISAS TECNOLÓGICASIPT; INSTITUTO GEOLÓGICO- IG; COMPANHIA DE PESQUISA DE RECURSOS MINERAIS-CPRM. Mapa de Águas Subterrâneas do Estado de São Paulo. Escala 1.000.000. São Paulo: DAEE, IPT, IG, CPRM, 2005.

ENVIRONMENTAL SYSTEMS RESEARCH INSTITUTEESRI. ArcGIS professional GIS for the desktop, versão 10.1. Software. 2012.

FOSTER, S. \& HIRATA, R. Avaliação do risco de poluição das águas subterrâneas: uma metodologia baseada em dados existentes. Organização Mundial de Saúde, Organização Panamericana de Saúde, Centro Panamericano de Engenharia Sanitária e Ciências Ambientais. Lima, 78p., 1988.

FOSTER, S.; HIRATA, R.; GOMES, D.; D’ELIA, M.; PARIS, M. Proteção da qualidade da água subterrânea: um guia para empresas de abastecimento de água, órgãos municipais e agências ambientais. Edição brasileira: SERVMAR - Serviços Técnicos Ambientais Ltda, Banco Mundial. 104p. 2006.

GASTMANS, D.; VEROSLAVSKY, G.; CHANG, H.K.; CAETANO-CHANG, M.R.; PRESSINOTTI, M. Modelo hidrogeológico conceptual del Sistema Acuífero Guaraní (SAG): una herramienta para la gestión. Boletín Geológico y Minero, v. 123, p. 249-265, 2012.

GEMAIL, KH.S.; EL-ALFY, M.; GHONEIM, M.F.; ELSHISHTAWY, A.M.; ABD ELBARY, M.H. Comparison of DRASTIC and DC resistivity modeling for assessing aquifer vulnerability in the central Nile Delta, Egypt. Environmental Earth Sciences, v. 76, n. 350, 2017.

GOLDEN SOFTWARE INC. SURFER 8 - User's guide/contouring and 3D surface mapping for scientists and engineers, versão 8. Software. 2002.

GOMES, M.A.F. (Ed.). Uso agrícola das áreas de afloramento do Aquífero Guarani no Brasil: implicações para a água subterrânea e propostas de gestão com enfoque agroambiental. Brasília: EMBRAPA, 417p., 2008.

HENRIET, J.P. Direct applications of the Dar Zarrouk parameters in ground water surveys. Geophysical Prospecting, n. 24, p. 344-353, 1975.

INTERPEX LIMITED. IX1D, versão 2. Software. 2008.

INSTITUTO DE PESQUISAS TECNOLÓGICAS DO ESTADO DE SÃO PAULO-IPT. Mapa Geológico do Estado de São Paulo. Escala 1:500.000. São Paulo: IPT, 1981. 2 v. (Monografias, 6; Publicação, 1 184).

INSTITUTO DE PESQUISAS TECNOLÓGICAS DO ESTADO DE SÃO PAULO-IPT. Sistema Aquífero Guarani: subsídios ao plano de desenvolvimento e proteção ambiental da área de afloramento do Sistema Aquífero Guarani no Estado de São Paulo. São Paulo: IPT, 2011.

INSTITUTO DE PESQUISAS TECNOLÓGICAS DO ESTADO DE SÃO PAULO - IPT; UNIVERSIDADE ESTADUAL PAULISTA-UNESP. Banco de dados geofísicos da bacia do Paraná. Rio Claro: IPT, Unesp. Projeto de pesquisa, 9p. 2013.

MAILLET, R. The fundamental equations of electrical prospecting. Geophysics, v. 12, n. 4, p. 529-556, 1947.

MICROSOFT CORPORATION. Microsoft Office Excel. Software. 2007. 
MOSURO, G.O.; ADEKOYA, F.; ATOBI, O.; BAYEWU, O.O.; LANIYAN, T.A.; OKUBENA, M.; OLORUNTOLA, M.O.; OMOSANYA, K.O.; POPOOLA, E. Assessment of groundwater vulnerability to leachate infiltration using electrical resistivity method. Applied Water Science, p. 1-1, 2016.

NDATUWONG, L.G. \& YADAV, G.S. Application of geoelectrical data to evaluate groundwater potential zone and assessment of overburden protective capacity in part of Sonebhadra district, Uttar Pradesh. Environmental Earth Sciences, v. 73, n. 7, p. 3655-3664, 2015.

NIAZ, A.; KHAN, M.R.; MUSTAFA, S.; HAMEED, F. Determination of aquifer properties and vulnerability mapping by using geoelectrical investigation of parts of Sub-Himalayas, Bhimber, Azad Jammu and Kashmir, Pakistan. Quarterly Journal of Engineering Geology and Hydrogeology, v. 49, p. 36-46, 2016.

ORELLANA, E. Prospección geoelectrica em corriente continua. Madrid: Paraninfo, Biblioteca Tecnica Philips, 1972, 523p.

ORGANIZAÇÃO DOS ESTADOS AMERICANOS - OEA. Aquífero Guarani: programa estratégico de ação - edição bilíngue. Argentina, Brasil, Paraguai e Uruguai: OEA, 424p. 2009

PAULA E SILVA, F. Geologia de subsuperfície e hidroestratigrafia do Grupo Bauru no Estado de São Paulo. 2003. 166 p. Tese (Doutorado em Geologia Regional) Instituto de Geociências e Ciências Exatas, Universidade Estadual Paulista, Rio Claro, 2003.
PAULIPETRO. Relatório de Atividades 1979/1981, 59p., 1981.

ROCHA, G.A. O grande manancial do Cone Sul. Estudos avançados: São Paulo, v. 11, n. 30, 1997.

SENDRÒS, A.; DIAZ, Y.; HIMI, M.; TAPIAS, J.C.; RIVERO, L.; FONT, X.; CASAS, A. An evaluation of aquifer vulnerability in two nitrate sensitive areas of Catalonia (NE Spain) based on electrical resistivity methods. Environmental Earth Sciences, v. 71, n. 1, p. 77-84, 2014.

SERVIÇO GEOLÓGICO DO BRASIL-CPRM. Aquífero Guarani. 2014. Disp. em: http://www.cprm.gov.br/publique /Redes-Institucionais/Rede-de-Bibliotecas---Rede-

Ametista/Canal-Escola/Aquifero-Guarani-2617.html. Acesso em: 05 jul. 2018.

SERVIÇO GEOLÓGICO DO BRASIL-CPRM. Sistema de Informações de Águas Subterrâneas - SIGAS. 2015. Disp. em: http://siagas.cprm.gov.br/layout/index.php. Acesso em: 02 out. 2015 .

VAN STEMPVOORT, D.; EWERT, L.; WASSENAAR, L. AVI: a method for groundwater protection mapping in the prairie provinces of Canada, 23p., 1992.

Submetido em 07 de novembro de 2017 Aceito em 04 de setembro de 2018 